\title{
Cournot vs. Bertrand in mixed markets with $\mathbf{R} \& \mathbf{D}^{\dagger}$
}

\author{
Debasmita Basak \\ Business School, University of Nottingham, UK \\ Leonard F.S. Wang \\ Wenlan School of Business, Zhongnan University of Economics and Law, \\ Wuhan, China
}

February 2019

\begin{abstract}
We investigate the question of endogenous choice of price and quantity competition in a mixed duopoly where both welfare maximising public firm and profit maximising private firm invest in cost-reducing $R \& D$. In contrary to the conventional belief that Cournot competition arises in equilibrium, we find that price competition constitutes equilibrium. We further argue that the results that Cournot profit is strictly higher than Bertrand in standard oligopoly and that the Bertrand profit is strictly higher than Cournot in mixed oligopoly, both hold when the public and private firm engage in $\mathrm{R} \& \mathrm{D}$. We also find that the public firm is more innovative than the private firm.
\end{abstract}

Key Words: Bertrand; Cournot; Differentiated products, Mixed markets, Process innovation JEL Classification: D43; H42; L13; O31

Correspondence to: Leonard F.S. Wang

Wenlan School of Business,

Zhongnan University of Economics and Law, 182\# Nanhu Avenue, East Lake High-Tech Development Zone, Wuhan 430073, Hubei, China

\footnotetext{
${ }^{\dagger}$ We would like to thank Toshihiro Matsumura and Arijit Mukherjee for helpful discussions and suggestions.
} 


\section{Introduction}

The debate on endogenous choice of competition modes, viz., price or quantity competition has gained popularity since the seminal contribution by Singh and Vives (1984) which established that in a private duopoly choosing quantity (price) contract is the dominant strategy for both firms when the goods are substitutes (complements). However, studies show that the private firms co-exist with public firms in several manufacturing and service industries, such as airlines, railways, steel, automobile, electric power suppliers in the EU, education, hospital, and banking (see Anderson et al., 1997; Matsumura, 1998). Naturally, the endogeneity of competition modes got renewed interest in mixed markets. For example, Matsumura and Ogawa (2012) showed that price contract is the dominant strategy for both public and private firms regardless of whether the goods are substitutes or complements. Scrimitore (2013) argued that quantity (price) can constitute dominant strategy when both firms receive a significantly high (low) amount of output subsidy. In a unionised mixed market, Choi (2012) found that while there exists a dominant strategy only for the public firm that chooses price competition; there is no dominant strategy for a private firm. In a more recent paper, allowing more than two private firms to compete against one public firm, Haraguchi and Matsumura (2016) showed that quantity competition arises in equilibrium.

While the above studies add value to the literature, firm's non-production activities such as, innovation remained relatively unexplored in this context. Research and development (R\&D) have a well-documented positive impact on growth and productivity of a nation. Therefore, it comes with no surprise that in mixed markets where both welfare benevolent public firms and profit oriented private firms compete with each other, allocate a significant amount of their budget towards innovation. ${ }^{1}$ For eg., the British public sectors spent $£ 1.453$

\footnotetext{
${ }^{1}$ See Delbono and Denicolló (1993), Nett (1994), Pal and White (1998), Nishimori and Ogawa (2002), Lin and Ogawa (2005), Ishibashi and Matsumura (2006) for some work on R\&D in mixed markets.
} 
billion on biomedical and health research in 1982 and this rose to $£ 3.429$ billion in 2012. Private pharmaceutical industry's R\&D spending in the UK, on the other hand, rose more rapidly from $£ 925$ million in 1982 to $£ 4.207$ billion in 2012 . Further statistical evidences ${ }^{2}$ reveal that in countries, such as USA, UK and Germany, two-thirds of nation's total investment comes from the private sectors and the rest is funded by its competitive rival that are public sectors. ${ }^{3}$

Motivated by the recent trends in R\&D in mixed markets, we consider a mixed market where both public and private firms invest in cost-reducing R\&D. First, we show that choosing price contract is the dominant strategy for both firms. Next, we argue that the findings that Cournot profit is strictly higher than Bertrand in standard oligopoly (Singh and Vives, 1984) ${ }^{4}$ and that the Bertrand profit is strictly higher than Cournot in mixed oligopoly (Ghosh and Mitra, 2010; Matsumura and Ogawa, 2012; Hirose and Matsumura, 2018), both hold if the welfare maximising public firm and profit maximising private firm engage in cost reducing R\&D.

Further, we show that the public firm is more innovative than the private firm regardless of the mode of competition. This result can be related to the literature that considers R\&D competition in a mixed duopoly. By employing a model of free entry Nett (1994) argues that profit maximising private firm has a greater incentive towards process innovation compared to a public firm as it shifts a larger amount of its funds to sunk cost to coexist with an aggressive, non-cooperative public firm. In contrast, using a patent race model, Ishibashi and Matsumura (2006) show that public firm overspends in R\&D from the viewpoint of social welfare. Bárcena-Ruiz (2008) extended Nett's (1994) model by considering a different

\footnotetext{
${ }^{2}$ As reported by The Guardian in 'The government has promised more R\&D. Where will the money come from?' (January 4, 2018).

${ }^{3}$ See Ishibashi and Matsumura (2006, pp. 1348) for further interesting examples in R\&D competition between public and private firms.

${ }^{4}$ See Cheng (1985), Tanaka (2001a, b), and Tasnádi (2006) who confirm the findings of Singh and Vives (1984) by extending the analysis to asymmetric oligopolies, general demand and cost conditions and vertical product differentiation.
} 
objective function for the public firm by taking the weighed sum of the consumer and producer surpluses, and shows that the public firms can be more innovative than the private firms. In a way, our result complements Ishibashi and Matsumura (2006) and Bárcena-Ruiz (2008), but contradicts Nett (1994) by showing that the public firm spends more in R\&D than its profit maximising rival.

The remainder of the paper is structured as follows. In Section 2, we introduce the model, Section 3 presents the results. Finally, Section 4 closes the paper with concluding remarks.

\section{The model}

We consider an economy with a welfare maximising state-owned public firm (firm 1) and a profit maximising private firm (firm 2) producing differentiated products. We consider the representative consumer's utility function as

$$
U\left(q_{i}, q_{j}\right)=a \sum_{i} q_{i}-\frac{1}{2} \sum_{i} q_{i}^{2}-\theta \sum_{i \neq j} q_{i} q_{j}+m
$$

where $m$ is the numeraire good and $q_{i}$ denotes the output of firm $i$ where $i, j=1,2$ and $i \neq j$. The parameter $\theta \in(-1,1)$ measures the degree of product differentiation. If $\theta>0$ the goods are substitutes and they are complements when $\theta<0$. Utility maximisation generates the inverse demand function $P_{i}=a-q_{i}-\theta q_{j}$. The firms produce under decreasing returns ${ }^{5}$ :

$$
C_{i}=\left(c-r_{i}\right) q_{i}+q_{i}^{2}
$$

\footnotetext{
${ }^{5}$ The assumption of decreasing returns to scale technologies, which can be motivated by capacity constraints or scarcity of resources, have been discussed extensively in different contexts (Tirole, 1988). Banker et al. (1994) show that decreasing returns may prevail in the software industry. Girma and Görg (2002) and Saal et al. (2007) found constant or decreasing returns in the UK industries. The typical two-digit industries in the US (Basu and Fernald, 1997), three-digit manufacturing industries in Singapore (Kee, 2002), Broadacre industries in Australia (Townsend et al., 1998) appear to have decreasing returns to scale.
} 
where $r_{i}$ represents firm $i$ 's investment in cost $(c)$ reduction and $c \in(0, a) .{ }^{6} \quad \mathrm{R} \& \mathrm{D}$ is expensive and costs $k r_{i}^{2}$, where $k$ measures the efficiency of $\mathrm{R} \& \mathrm{D}$ technology. To avoid analytical complexity and unnecessary complications, we however, normalise $k$ to unity as this does not add much value to our work. For notational easy we assume $\lambda_{i} \equiv c-r_{i}$.

The state-owned public firm maximises the social welfare (SW) which is defined as the sum of consumer surplus (CS) and producer surplus (PS):

$$
\begin{aligned}
S W & =\underbrace{U\left(q_{i}, q_{j}\right)-\sum_{i=1}^{2} P_{i} q_{i}}_{\mathrm{CS}}+\underbrace{\sum_{i=1}^{2}\left(P_{i} q_{i}-C_{i}\right)-\sum_{i=1}^{2} r_{i}^{2}}_{\mathrm{PS}} \\
& =U\left(q_{i}, q_{j}\right)-\sum_{i=1}^{2} C_{i}-\sum_{i=1}^{2} r_{i}^{2}
\end{aligned}
$$

And, the private firm, maximises its own profit level

$$
\pi_{2}=\left(P_{2} q_{2}-C_{2}\right)-r_{2}^{2}
$$

We develop a model of three stage game that unfolds as follows. At stage 1, each firm simultaneously chooses whether to adopt quantity contract $(q)$ or price contract $(p)$. At stage 2, each firm invests in R\&D. At stage 3, firms compete contingent to the decisions made in stage 1 and maximise their respective profits. We solve the game through backward induction to find the subgame perfect Nash equilibrium.

\section{1 (quantity - quantity) contract}

Assume that both firms compete in quantities. Firm 1 maximises (2) with respect to $q_{1}$ whereas firm 2 maximises (3) with respect to $q_{2}$. Solving the first order conditions $\left(\frac{\partial S W}{\partial q_{1}}=0 \& \frac{\partial \pi_{2}}{\partial q_{2}}=\right.$ 0) we obtain:

\footnotetext{
${ }^{6}$ The specifications of the cost structure is similar to Gil-Moltó et al. (2011) who analysed the role of R\&D subsidies and Kesavayuth and Zikos (2013) who studied the welfare effects of R\&D and an output subsidy in the context of mixed market.
} 


$$
\begin{aligned}
& q_{1}^{q q}=\frac{a(4-\theta)-4 \lambda_{1}+\theta \lambda_{2}}{12-\theta^{2}} \\
& q_{2}^{q q}=\frac{a(3-\theta)+\theta \lambda_{1}-3 \lambda_{2}}{12-\theta^{2}}
\end{aligned}
$$

Using (4) and (5), firms' objective functions in (2) and (3) reduce to

$$
\begin{gathered}
S W^{q q}=\frac{1}{2}\left(3 q_{1}^{2}+2 \theta q_{1} q_{2}+5 q_{2}^{2}\right)-\left(r_{1}^{2}+r_{2}^{2}\right) \\
\pi_{2}^{q q}=2 q_{2}^{2}-r_{2}^{2}
\end{gathered}
$$

At the $R \& D$ stage the public firm and the private firm derive their optimal $R \& D$ levels by maximising (6) and (7) with respect to $r_{1}$ and $r_{2}$ respectively. ${ }^{7}$ We get the equilibrium R\&D spending as:

$$
\begin{gathered}
r_{1}^{q q}=\frac{(a-c)\left(42-15 \theta-3 \theta^{2}+\theta^{3}\right)}{210-45 \theta^{2}+2 \theta^{4}}>0 \\
r_{2}^{q q}=\frac{6(a-c)(5-2 \theta)}{210-45 \theta^{2}+2 \theta^{4}}>0
\end{gathered}
$$

Next, we find the equilibrium social welfare and profit of firm 2.

$$
\begin{gathered}
S W^{q q}=\frac{2(a-c)^{2}\left(33840-12960 \theta-9543 \theta^{2}+3660 \theta^{3}+789 \theta^{4}-300 \theta^{5}-22 \theta^{6}+8 \theta^{7}\right)}{2\left(210-45 \theta^{2}+2 \theta^{4}\right)^{2}}>0 \\
\pi_{2}^{q q}=\frac{2(a-c)^{2}(5-2 \theta)^{2}\left(126-24 \theta^{2}+\theta^{4}\right)}{\left(210-45 \theta^{2}+2 \theta^{4}\right)^{2}}>0
\end{gathered}
$$

\section{2 (price - price) contract}

Next, assume that both firms compete in prices. Accordingly, the public firm and private firm maximise (2) and (3) with respect to $P_{1}$ and $P_{2}$ respectively. Solving the first-order conditions $\left(\frac{\partial S W}{\partial P_{1}}=0 \& \frac{\partial \pi_{2}}{\partial P_{2}}=0\right)$ the equilibrium price and quantity can be found as

\footnotetext{
${ }^{7}$ Second order conditions are met, $\frac{d^{2} S W^{q q}}{d r_{1}^{q q^{2}}}=-\frac{240-45 \theta^{2}+2 \theta^{4}}{\left(12-\theta^{2}\right)^{2}}<0$ and $\frac{d^{2} \pi_{2}^{q q}}{d r_{2}^{q q^{2}}}=-\frac{2\left(126-24 \theta^{2}+\theta^{4}\right)}{\left(12-\theta^{2}\right)^{2}}<0$ for $\theta \in(-1,1)$.
} 


$$
\begin{gathered}
P_{1}^{p p}=\frac{a\left(8-\theta-3 \theta^{2}-\theta^{3}+\theta^{4}\right)+2\left(2-\theta^{2}\right) \lambda_{1}+\theta\left(1+\theta^{2}\right) \lambda_{2}}{12-5 \theta^{2}+\theta^{4}} \\
P_{2}^{p p}=\frac{a\left(3-\theta^{2}\right)(3-\theta)+\theta\left(3-\theta^{2}\right) \lambda_{1}+\left(3-2 \theta^{2}+\theta^{4}\right) \lambda_{2}}{12-5 \theta^{2}+\theta^{4}}
\end{gathered}
$$

and, $\quad q_{1}^{p p}=\frac{a\left(4-2 \theta-\theta^{2}+\theta^{3}\right)-\left(4-\theta^{2}\right) \lambda_{1}+\theta\left(2-\theta^{2}\right) \lambda_{2}}{12-5 \theta^{2}+\theta^{4}}$

$$
q_{2}^{p p}=\frac{a(3-\theta)+\theta \lambda_{1}-3 \lambda_{2}}{12-5 \theta^{2}+\theta^{4}}
$$

Substituting (10) and (11) in (2) and (3), we re-write firms' objective functions as

$$
\begin{gathered}
S W^{p p}=\eta_{1} q_{1}+\frac{1}{2}\left(q_{1}^{2}+2 \theta q_{1} q_{2}+5 q_{2}^{2}-2 \theta^{2} q_{2}^{2}\right)-\left(r_{1}^{2}+r_{2}^{2}\right) \\
\pi_{2}^{p p}=\left(2-\theta^{2}\right) q_{2}^{2}-r_{2}^{2}
\end{gathered}
$$

where $\eta_{1}=\frac{a\left(4+\theta-2 \theta^{2}-2 \theta^{3}+\theta^{4}\right)-\left(4-2 \theta^{2}+\theta^{4}\right) \lambda_{1}-\theta\left(1-2 \theta^{2}\right) \lambda_{2}}{12-5 \theta^{2}+\theta^{4}}$.

Next, the firms decide their optimal R\&D levels by maximising (12) and (13) with respect to $r_{1}$ and $r_{2}$ which give: ${ }^{8}$

$$
\begin{gathered}
r_{1}^{p p}=\frac{(a-c)\left(42-15 \theta-32 \theta^{2}+10 \theta^{3}+13 \theta^{4}-4 \theta^{5}-2 \theta^{6}+\theta^{7}\right)}{210-190 \theta^{2}+85 \theta^{4}-18 \theta^{6}+2 \theta^{8}}>0 \\
r_{2}^{p p}=\frac{3(a-c)(5-2 \theta)\left(2-\theta^{2}\right)}{210-190 \theta^{2}+85 \theta^{4}-18 \theta^{6}+2 \theta^{8}}>0
\end{gathered}
$$

Straightforward calculations yield:

$$
\begin{gathered}
S W^{p p}=\frac{(a-c)^{2} \eta_{2}}{2\left(210-190 \theta^{2}+85 \theta^{4}-18 \theta^{6}+2 \theta^{8}\right)^{2}}>0 \\
\pi_{2}^{p p}=\frac{2(a-c)^{2}(5-2 \theta)^{2}\left(2-\theta^{2}\right)\left(126-111 \theta^{2}+49 \theta^{4}-10 \theta^{6}+\theta^{8}\right)}{\left(210-190 \theta^{2}+85 \theta^{4}-18 \theta^{6}+2 \theta^{8}\right)^{2}}>0
\end{gathered}
$$

\footnotetext{
${ }^{8}$ The second order conditions are satisfied, $\frac{d^{2} S W^{p p}}{d r_{1}^{p p^{2}}}=-\frac{\left(18 \theta^{4}+205\right)\left(1-\theta^{2}\right)+\left(35+67 \theta^{4}+2 \theta^{8}\right)}{\left(12-5 \theta^{2}+\theta^{4}\right)^{2}}<0$ and $\frac{d^{2} \pi_{2}^{p p}}{d r_{2}^{p p^{2}}}=-2\left(\frac{\left(111+10 \theta^{4}\right)\left(1-\theta^{2}\right)+\left(15+39 \theta^{4}+\theta^{8}\right)}{\left(12-5 \theta^{2}+\theta^{4}\right)^{2}}\right)<0$ for $\theta \in(-1,1)$
} 
where, $\eta_{2}=\left(33840-12960 \theta-54903 \theta^{2}+20460 \theta^{3}+45603 \theta^{4}-16780 \theta^{5}-23488 \theta^{6}+\right.$ $\left.8720 \theta^{7}+7993 \theta^{8}-3020 \theta^{9}-1809 \theta^{10}+708 \theta^{11}+254 \theta^{12}-104 \theta^{13}-18 \theta^{14}+8 \theta^{15}\right)$.

\section{3 (price - quantity) contract}

Now, suppose that the public firm adopts the price contract whereas the private firm adopts the quantity contract. Therefore, firm 1 maximises (2) with respect to $P_{1}$ and firm 2 maximises (3) with respect to $q_{2}$. The first-order conditions $\left(\frac{\partial S W}{\partial P_{1}}=0 \& \frac{\partial \pi_{2}}{\partial q_{2}}=0\right)$ give

$$
\begin{aligned}
P_{1}^{p q} & =\frac{a\left(4-\theta-\theta^{2}\right)+\left(2-\theta^{2}\right) \lambda_{1}+\theta \lambda_{2}}{2\left(3-\theta^{2}\right)} \\
q_{2}^{p q} & =\frac{a(3-\theta)+\theta \lambda_{1}-3 \lambda_{2}}{4\left(3-\theta^{2}\right)}
\end{aligned}
$$

Using (16) and (17) in (2) and (3) give:

$$
\begin{gathered}
S W^{p q}=\frac{1}{2}\left(3 q_{1}^{2}+2 \theta q_{1} q_{2}+5 q_{2}^{2}-2 \theta^{2} q_{2}^{2}\right)-\left(r_{1}^{2}+r_{2}^{2}\right) \\
\pi_{2}^{p q}=\left(2-\theta^{2}\right) q_{2}^{2}-r_{2}^{2}
\end{gathered}
$$

Maximising the above with respect to $r_{1}$ and $r_{2}$ yield $^{9}$

$$
\begin{gathered}
r_{1}^{p q}=\frac{(a-c)\left(42-15 \theta-24 \theta^{2}+7 \theta^{3}+3 \theta^{4}\right)}{210-150 \theta^{2}+29 \theta^{4}}>0 \\
r_{2}^{p q}=\frac{3(a-c)(5-2 \theta)\left(2-\theta^{2}\right)}{210-150 \theta^{2}+29 \theta^{4}}>0
\end{gathered}
$$

Substituting the above in (18) and (19) gives:

$$
\begin{gathered}
S W^{p q}=\frac{(a-c)^{2}\left(33840-12960 \theta-41583 \theta^{2}+15180 \theta^{3}+18336 \theta^{4}-6000 \theta^{5}-3295 \theta^{6}+812 \theta^{7}+174 \theta^{8}\right)}{2\left(210-150 \theta^{2}+29 \theta^{4}\right)^{2}}>0 \\
\pi_{2}^{p q}=\frac{(a-c)^{2}(5-2 \theta)^{2}\left(2-\theta^{2}\right)\left(126-87 \theta^{2}+16 \theta^{4}\right)}{\left(210-150 \theta^{2}+29 \theta^{4}\right)^{2}}>0
\end{gathered}
$$

\footnotetext{
${ }^{9}$ Second order conditions are met, $\frac{d^{2} S W^{p q}}{d r_{1}^{p q^{2}}}=-\frac{240-165 \theta^{2}+29 \theta^{4}}{16\left(3-\theta^{2}\right)^{2}}<0$ and $\frac{d^{2} \pi_{2}^{p q}}{d r_{2}^{p q^{2}}}=-\frac{126-87 \theta^{2}+16 \theta^{4}}{8\left(3-\theta^{2}\right)^{2}}<0$ for $\theta \in(-1,1)$.
} 


\section{4 (quantity - price) contract}

Finally, assume that the public firm chooses quantity and the private firm chooses price contract. Firm 1 and firm 2, in this case, maximises (2) and (3) with respect to $q_{1}$ and $P_{2}$ respectively. Solving the first-order conditions $\left(\frac{\partial S W}{\partial q_{1}}=0 \& \frac{\partial \pi_{2}}{\partial P_{2}}=0\right)$, we find

$$
\begin{aligned}
q_{1}^{q p} & =\frac{a(2-\theta)-2 \lambda_{1}+\theta \lambda_{2}}{\left(6-\theta^{2}\right)} \\
P_{2}^{q p} & =\frac{3 a(3-\theta)+3 \theta \lambda_{1}-\left(3-2 \theta^{2}\right) \lambda_{2}}{2\left(6-\theta^{2}\right)}
\end{aligned}
$$

Using (6) and (7) in (2) and (3) gives

$$
\begin{gathered}
S W^{q p}=q_{1} \eta_{3}+\frac{1}{2}\left(q_{1}^{2}+2 \theta q_{1} q_{2}+5 q_{2}^{2}\right)-\left(r_{1}^{2}+r_{2}^{2}\right) \\
\pi_{2}^{q p}=2 q_{2}^{2}-r_{2}^{2}
\end{gathered}
$$

where $\eta_{3}=\left(\frac{a\left(4+\theta-\theta^{2}\right)-\left(4-\theta^{2}\right) \lambda_{1}-\theta \lambda_{2}}{2\left(6-\theta^{2}\right)}\right)$.

We obtain the equilibrium R\&D investments by maximising (24) and (25) with respect to $r_{1}$ and $r_{2}$ respectively. ${ }^{10}$

$$
\begin{gathered}
r_{1}^{q p}=\frac{(a-c)(2-\theta)\left(21+3 \theta-4 \theta^{2}\right)}{210-85 \theta^{2}+8 \theta^{4}}>0 \\
r_{2}^{q p}=\frac{6(a-c)(5-2 \theta)}{210-85 \theta^{2}+8 \theta^{4}}>0
\end{gathered}
$$

Straightforward calculations give

$$
\begin{gathered}
S W^{q p}=\frac{(a-c)^{2}\left(33840-12960 \theta-22863 \theta^{2}+8940 \theta^{3}+4746 \theta^{4}-1840 \theta^{5}-336 \theta^{6}+128 \theta^{7}\right)}{2\left(210-85 \theta^{2}+8 \theta^{4}\right)^{2}}>0 \\
\pi_{2}^{q p}=\frac{4(a-c)^{2}(5-2 \theta)^{2}\left(63-24 \theta^{2}+2 \theta^{4}\right)}{\left(210-85 \theta^{2}+8 \theta^{4}\right)^{2}}>0
\end{gathered}
$$

The discussions establish the following Lemma.

\footnotetext{
${ }^{10}$ The second order conditions hold, $\frac{d^{2} S W^{q p}}{d r_{1}^{q p^{2}}}=-\frac{240-85 \theta^{2}+8 \theta^{4}}{4\left(6-\theta^{2}\right)^{2}}<0$ and $\frac{d^{2} \pi_{2}^{q p}}{d r_{2}^{q p^{2}}}=-\frac{63-24 \theta^{2}+2 \theta^{4}}{\left(6-\theta^{2}\right)^{2}}<0$ for $\theta \in(-1,1)$.
} 
Lemma 1: Assume that $\theta \neq 0$. The public firm produces more than the private firm and the former invests more in $R \& D$ than the latter.

Proof: It can be checked that $q_{1}^{q q}-q_{2}^{q q}=\frac{(a-c)(3+\theta)(8-3 \theta)}{210-45 \theta^{2}+2 \theta^{4}}>0 \quad$ and $q_{1}^{p p}-q_{2}^{p p}=\frac{(a-c)\left[\left(21+11 \theta^{4}+2 \theta^{5}\right)(1-\theta)+3\left(1+11 \theta^{2}+10 \theta^{3}\right)+2 \theta^{7}\right]}{2\left(95+9 \theta^{4}\right)\left(1-\theta^{2}\right)+\left(20+67 \theta^{4}+2 \theta^{8}\right)}>0$. Also check that $r_{1}^{q q}-$ $r_{2}^{q q}=\frac{(a-c)\left(12-3 \theta-3 \theta^{2}+\theta^{3}\right)}{210-45 \theta^{2}+2 \theta^{4}}>0$ and $r_{1}^{p p}-r_{2}^{p p}=\frac{(1-\theta)\left(3+4 \theta^{3}+4 \theta^{4}\right)+\theta^{4}\left(13-2 \theta^{2}\right)+\left(9+17 \theta^{2}+\theta^{7}\right)}{2\left(95+9 \theta^{4}\right)\left(1-\theta^{2}\right)+\left(20+67 \theta^{4}+2 \theta^{8}\right)}>0$.

Lemma 1 states that the public firm produces more than the private firm regardless of the mode of competition, i.e., Cournot or Bertrand. And, investments in R\&D being socially desirable, the public firm also invests more than the private, whereas the private firm simply free-rides on public firm's investments.

At this stage, it is worth pointing out that it is not clear a-priori whether the public firm produces under higher marginal cost than that of a private firm. Straightforward calculations show that the public firm faces a higher marginal cost of production compared to a private firm, ${ }^{11}$ meaning that distributional inefficiency that arises due to cost of production would have reduced should the last few units of output were produced by the private firm.

\section{Results}

We now analyse the first stage of the game where the firms decide whether to adopt price or quantity contract. Table 1 summarises the possible strategies of each firm and the realised profit of firm 2 and associated welfare.

\footnotetext{
${ }^{11}$ See that $M C_{1}^{q q}-M C_{2}^{q q}=\frac{(a-c)\left(36+\theta-3 \theta^{2}-\theta^{3}\right)}{210-45 \theta^{2}+2 \theta^{4}}>0$ and $M C_{1}^{p p}-M C_{2}^{p p}=\frac{(a-c)(1-\theta)\left(36-3 \theta-52 \theta^{2}+4 \theta^{3}+17 \theta^{4}-\theta^{5}-3 \theta^{6}\right)}{210-190 \theta^{2}+85 \theta^{4}-18 \theta^{6}+2 \theta^{8}}>0$ where $M C_{i}=\left(c-x_{i}\right)+2 q_{i}$.
} 
Table 1: First stage game

Firm 2

\begin{tabular}{|c|c|c|c|}
\hline & & Quantity & Price \\
\hline Firm 1 & $\begin{array}{c}\text { Quantity } \\
\text { Price }\end{array}$ & $\begin{array}{l}S W^{q q}, \pi_{2}^{q q} \\
S W^{p q}, \pi_{2}^{p q}\end{array}$ & $\begin{array}{l}S W^{q p}, \pi_{2}^{q p} \\
s W^{p p}, \pi_{2}^{p p}\end{array}$ \\
\hline
\end{tabular}

Proposition 1: If $\theta \neq 0$, choosing price contract is the dominant strategy for both firms.

Proof: Check that: $S W^{p p}-S W^{q p}=\frac{\theta^{2}(a-c)^{2}(5-2 \theta)^{2} \lambda_{1}}{2\left(210-85 \theta^{2}+8 \theta^{4}\right)^{2}\left(210-190 \theta^{2}+85 \theta^{4}-18 \theta^{6}+2 \theta^{8}\right)^{2}}>0$,

$$
\begin{aligned}
& S W^{p q}-S W^{q q}=\frac{3 \theta^{2}(a-c)^{2}(5-2 \theta)^{2}\left(1058400-1743840 \theta^{2}+1065015 \theta^{4}-305472 \theta^{6}+41640 \theta^{8}-2529 \theta^{10}+58 \theta^{12}\right)}{2\left(210-45 \theta^{2}+2 \theta^{4}\right)^{2}\left(210-150 \theta^{2}+29 \theta^{4}\right)^{2}}>0, \\
& \pi_{2}^{p p}-\pi_{2}^{q p}=\frac{\theta^{2}(a-c)^{2}\left(1-\theta^{2}\right)(5-2 \theta)^{2}\left(2-\theta^{2}\right) \lambda_{2}}{\left(210-150 \theta^{2}+29 \theta^{4}\right)^{2}\left(210-190 \theta^{2}+85 \theta^{4}-18 \theta^{6}+2 \theta^{8}\right)^{2}}>0 \\
& \pi_{2}^{q p}-\pi_{2}^{q q}=\frac{2 \theta^{2}(a-c)^{2}(5-2 \theta)^{2}\left(1058400-790020 \theta^{2}+225300 \theta^{4}-30685 \theta^{6}+1984 \theta^{8}-48 \theta^{10}\right)}{\left(210-45 \theta^{2}+2 \theta^{4}\right)^{2}\left(210-85 \theta^{2}+8 \theta^{4}\right)^{2}}>0
\end{aligned}
$$

where,

$\lambda_{1}=\left(3175200-5874120 \theta^{2}+4658085 \theta^{4}-2054313 \theta^{6}+491123 \theta^{8}-26085 \theta^{10}-20957 \theta^{12}+6818 \theta^{14}-910 \theta^{16}+48 \theta^{18}\right)>0$ and

$\lambda_{2}=\left(1058400-2113020 \theta^{2}+1959060 \theta^{4}-1090504 \theta^{6}+395860 \theta^{8}-95735 \theta^{10}+15115 \theta^{12}-1436 \theta^{14}+64 \theta^{16}\right)>0$.

The reasoning of the proposition goes as follows. We begin by assuming that the goods are substitutes and justify why choosing price contract is the best strategy for the public firm. Note that, process $R \& D$ reduces firm's unit cost of production which generates more output. This 
creates a direct positive effect on social welfare. Second, it is easy to see that the R\&D investments act as strategic substitutes for substitutable products, meaning that investment by a typical firm reduces its rival's output thus creating an indirect negative effect on welfare. Straightforward calculations show that regardless of whether the private firm chooses the price contract or quantity contract, the public firm always invests more under quantity competition than price competition when the goods are substitutes. ${ }^{12}$ This implies that the reduction in rival firm's output and hence, the loss in social welfare is also higher under the former competition than the latter. Therefore, the public firm always favours price contract to minimise the welfare loss.

We now consider the case where the goods are complements and again explain why choosing price contract becomes the dominant strategy for the public firm. As cost reduction in $R \& D$ boosts output regardless of the type of goods, the direct positive effect on social welfare remains even when the goods are complements. Second, we find that R\&D investments act as strategic complements for complementary products. This means an investment by a typical firm increases its rival's output which again creates a positive effect on social welfare. As follows from Lemma 1, the public firm always invests more under price competition than quantity competition no matter whether the private firm chooses the price or quantity contract. This means that the rise in rival firm's output and hence, the gain in social welfare is also higher under the latter competition than the former. Therefore, it follows naturally that the public firm chooses price contract to maximise its gain in social welfare.

Next, we discuss why choosing price contract is the best response for the private firm. Note that, R\&D creates two opposing effects on profit. First, for a given cost reduction, higher

\footnotetext{
${ }^{12}$ See that $r_{1}^{q p}-r_{1}^{p p}=\frac{\theta^{3}(a-c)(5-2 \theta)\left(63-45 \theta^{2}-4 \theta^{4}+3 \theta^{6}\right)}{\left(210-85 \theta^{2}+8 \theta^{4}\right)\left(210-190 \theta^{2}+85 \theta^{4}-18 \theta^{6}+2 \theta^{8}\right)}>0, r_{1}^{q q}-r_{1}^{p q}=\frac{3 \theta^{3}(a-c)(5-2 \theta)\left(21-16 \theta^{2}+\theta^{4}\right)}{\left(210-45 \theta^{2}+2 \theta^{4}\right)\left(210-150 \theta^{2}+29 \theta^{4}\right)}>0$ for $\theta \in(0,1)$ and the inequality signs reverse for $\theta \in(-1,0)$.
} 
output breeds larger profit. We call this a positive output effect. Second, R\&D activity being costly, it creates adverse effects on profit. We name this as negative cost effect. We find that irrespective of whether the public firm adopts the price contract or quantity contract, the private firm produces and invests more under the Bertrand competition compared to Cournot ${ }^{13}$ and the positive output effect always dominates the negative cost effect on profit if the private firm chooses price competition. This holds true for both substitutable and complementary products. Hence, the private firm always prefers price contract to quantity contract.

The following results are also worth noting.

Proposition 2: Assume that $\theta \neq 0$. The private firm earns a higher profit under Bertrand competition than under Cournot competition if $-0.92 \leq \theta \leq 0.92$, while the opposite holds for $-1<\theta<-0.92$ and $0.92<\theta<1$.

Proof: It can be checked that $\Delta \pi_{2}=\pi_{2}^{q q}-\pi_{2}^{p p}=\frac{\theta^{2}(a-c)^{2}(5-2 \theta)^{2} v_{1}}{\left(210-45 \theta^{2}+2 \theta^{4}\right)^{2}\left(210-190 \theta^{2}+85 \theta^{4}-18 \theta^{6}+2 \theta^{8}\right)^{2}}$ and $\Delta \pi_{2}<0$ for $-0.92 \leq \theta \leq 0.92$ and $\Delta \pi_{2}>0$ for $-1<\theta<-0.92$ and $0.92<\theta<1$ where $v_{1}=\left(2116800-5496120 \theta^{2}+5615340 \theta^{4}-3317207 \theta^{6}+1250203 \theta^{8}-313962 \theta^{10}+52355 \theta^{12}-5564 \theta^{14}+332 \theta^{16}-8 \theta^{18}\right)$.

It is easy to check that irrespective of the degree of product differentiation, the private firm in our work, produces more when the competition is in prices than in quantities. ${ }^{14}$ Further, if

\footnotetext{
${ }^{13}$ Check that $q_{2}^{p p}-q_{2}^{p q}=\frac{\theta^{2}(a-c)\left(1-\theta^{2}\right)(5-2 \theta)\left(270-202 \theta^{2}+59 \theta^{4}-8 \theta^{6}\right)}{\left(210-150 \theta^{2}+29 \theta^{4}\right)\left(210-190 \theta^{2}+85 \theta^{4}-18 \theta^{6}+2 \theta^{8}\right)}>0, q_{2}^{q p}-q_{2}^{q q}=\frac{\theta^{2}(a-c)(5-2 \theta)\left(10-\theta^{2}\right)\left(27-4 \theta^{2}\right)}{\left(210-45 \theta^{2}+2 \theta^{4}\right)\left(210-85 \theta^{2}+8 \theta^{4}\right)}>0$ and $r_{2}^{p p}-r_{2}^{p q}=\frac{6 \theta^{2}(a-c)\left(1-\theta^{2}\right)(5-2 \theta)\left(2-\theta^{2}\right)\left(20-8 \theta^{2}+\theta^{4}\right)}{\left(210-150 \theta^{2}+29 \theta^{4}\right)\left(210-190 \theta^{2}+85 \theta^{4}-18 \theta^{6}+2 \theta^{8}\right)}>0, r_{2}^{q p}-r_{2}^{q q}=\frac{12 \theta^{2}(a-c)(5-2 \theta)\left(20-3 \theta^{2}\right)}{\left(210-45 \theta^{2}+2 \theta^{4}\right)\left(210-85 \theta^{2}+8 \theta^{4}\right)}>0$ if $\theta \neq 0$.

${ }^{14}$ Check that $q_{2}^{p p}-q_{2}^{q q}=\frac{\theta^{2}(a-c)(5-2 \theta)\left(900-751 \theta^{2}+246 \theta^{4}-40 \theta^{6}+2 \theta^{8}\right)}{\left(210-45 \theta^{2}+2 \theta^{4}\right)\left(210-190 \theta^{2}+85 \theta^{4}-18 \theta^{6}+2 \theta^{8}\right)}>0$ for $\theta \in(-1,1)$.
} 
$\theta \in[-0.92,0.92]$ the private firm's investment in $\mathrm{R} \& \mathrm{D}$ is also higher in the former competition than the latter whereas the reverse holds for $\theta \in(-1,-0.92)$ and $\theta \in(0.92,1) .{ }^{15}$ As follows, when the products are moderately differentiated (i.e., $-0.92 \leq \theta \leq 0.92$ ) meaning that the product market competition is not so fierce, the benefit from $\mathrm{R} \& \mathrm{D}$ via positive output effect outweighs the negative cost effect thus giving rise to larger profit under price contract than quantity contract. The opposite happens when the goods are close to perfect substitutes (i.e., $\theta \rightarrow 1$ ) or perfect complements $($ i.e., $\theta \rightarrow-1)$ resulting in higher profit under Cournot than Bertrand competition. This result is in sharp contrast with Ghosh and Mitra (2010) and Matsumura and Ogawa (2012).

Proposition 3: Bertrand competition yields higher social welfare than Cournot competition.

Proof: Check that $S W^{p p}-S W^{q q}=\frac{\theta^{2}(a-c)^{2}(5-2 \theta)^{2} v_{2}}{2\left(210-45 \theta^{2}+2 \theta^{4}\right)^{2}\left(210-190 \theta^{2}+85 \theta^{4}-18 \theta^{6}+2 \theta^{8}\right)^{2}}>0$ if $\theta \neq 0$, where $v_{2}=\left(2419200-3600180 \theta^{2}+2051085 \theta^{4}-571773 \theta^{6}+10303 \theta^{8}+43980 \theta^{10}-14835 \theta^{12}+2178 \theta^{14}-146 \theta^{16}+4 \theta^{18}\right)>0$.

The result above shows that the level of social welfare is higher under Bertrand competition than under Cournot. This affirms the results of Singh and Vives (1984) and Ghosh and Mitra (2010) who show that Bertrand competition yields higher welfare than Cournot in private oligopoly and mixed oligopoly respectively. The welfare ordering obtained in our model, however, differs from the one derived by Hirose and Matsumura (2018) who adopt a model of

\footnotetext{
15 See that $\Delta r_{2}=r_{2}^{p p}-r_{2}^{q q}=\frac{3(a-c) \theta^{2}(5-2 \theta)\left(80-121 \theta^{2}+34 \theta^{4}-4 \theta^{6}\right)}{\left(210-45 \theta^{2}+2 \theta^{4}\right)\left(210-190 \theta^{2}+85 \theta^{4}-18 \theta^{6}+2 \theta^{8}\right)} \quad$ where $\Delta r_{2}>0$ for $-0.92 \leq \theta \leq 0.92$, and $\Delta r_{2}<0$ for $-1<\theta<-0.92$ and $0.92<\theta<1$.
} 
Stackelberg leadership. Although they find that Bertrand welfare is higher than Cournot welfare under public leadership, the welfare ranking is not so straightforward when the private firm is a Stackelberg leader. They show that under private leadership the welfare can be higher under Cournot competition than Bertrand if the foreign ownership in the private firm is significantly low. Our results, therefore, show that the standard welfare ranking is more common even when both public and private firm invest in cost reducing $R \& D$.

\section{Conclusion}

Over years, the endogenous choice of competition mode has been studied extensively. However, firm's non-production activities such as innovation has received relatively less attention in this context. We revisit the classic discussion of the endogenous choice of price and quantity contract in a mixed duopoly setting where both public firm and private firm engage in cost reducing $R \& D$. In contrary to the traditional belief that quantity competition constitutes equilibrium, we show that price competition arises in equilibrium. Further, we find that the private firm accrues higher profit under Cournot competition than Bertrand when the goods are close to perfect substitutes or perfect complements. We also show that the public firm spends more towards R\&D compared to the private firm where the latter chooses to free ride on public firm's investments in innovation. Our results indicate that when the state-owned public firm compete in prices with its rival, it should engage in $R \& D$ more actively compared to when it competes in quantity as the overall welfare improves under the former competition mode. To this end, our results offer valuable insights on firms' $R \& D$ strategies and policymakers' take on privatisation.

Finally, in spirit of the present paper we remark on the areas that remained unexplored.

First, our paper nests on the assumption that both welfare maximising public firm and profit maximising private firm invest only in costs-reducing R\&D. However, firms typically finance 
in both product and process innovation and therefore, it would be interesting to check how our results change in such cases. Second, it would be interesting to see the effect of competition on firms' R\&D efforts. To this end it is natural to assume that there could be a large number of private firms that allocate their budget towards R\&D and compete against a nationalised firm. Third, the literature in mixed oligopoly predominantly assume that both public and private firms operate and compete in the same country. Our model made no exception to this assumption. However, with the wave of globalisation where foreign competition plays a pivotal role, one may want to explore how a public firm or private firm that is based in a foreign land and invests in process R\&D will affect our findings. Another natural extension could be to explore the case of licensing where one of the firms (either private or public firm) that possesses a superior technology may choose to licence it to its rival. It would be equally intriguing to look into the situation where one of the firms is partially privatised as opposed to fully privatised firm. As these issues deserve a detailed analysis, we leave them for future research. 


\section{References}

Anderson, S.P., A. de Palma and J.-F. Thisse, 1997, 'Privatization and efficiency in a differentiated industry', European Economic Review, 41: 1635-1654.

Banker, R.D., H. Chang and C.F. Kemerer, 1994, 'Evidence on economies of scale in software development', Information and Software Technology, 36: 275-282.

Bárcena-Ruiz, J. C., 2008, 'Are the public firms more innovative than the private ones?' Prague Economic Papers, 3: 157-167.

Basu, S. and J.G. Fernald, 1997, 'Returns to scale in U.S. production: estimates and implications', Journal of Political Economy, 105: 249-283.

Cheng, L., 1985, 'Comparing Bertrand and Cournot equilibria: a geometric approach', RAND Journal of Economics, 16(1): 146-152.

Choi, K., 2012, 'Price and quantity competition in a unionized mixed duopoly: the cases of substitutes and complements', Australian Economic Papers, 51: 1-22.

Delbono, F. and V. Denicoló, 1993, 'Regulating Innovative Activity: The Role of a Public Firm', International Journal of Industrial Organization, 11: 35-48.

Ghosh, A. and M. Mitra, 2010, 'Comparing Bertrand and Cournot in mixed markets', Economics Letters, 109 (2): 72-74.

Gil-Moltó, M.J., Poyago-Theotoky, J., and V. Zikos, 2011, 'R\&D Subsidies, Spillovers and Privatization in Mixed Markets', Southern Economic Journal, 78(1): 233-255.

Girma, S. and H. Görg, 2002, 'Foreign Ownership, Returns to Scale and Productivity: Evidence from UK Manufacturing Establishments', CEPR Discussion Papers, No. 3503.

Haraguchi, J. and T. Matsumura, 2016, 'Cournot-Bertrand comparison in a mixed oligopoly', Journal of Economics', 117(2): 117-136. 
Hirose, K. and T. Matsumura, 2018, 'Comparing welfare and profit in quantity and price competition within Stackelberg mixed duopolies', Journal of Economics, 126(1): 75-93.

Ishibashi, I. and T. Matsumura, 2006, 'R\&D competition between public and private sectors', European Economic Review, 50: 1347-1366.

Kee, H. L., 2002, “Markups, returns to scale and productivity: a case of Singapore's manufacturing sector, Mimeo.

Kesavayuth, D., and V. Zikos, 2013, 'R\&D versus Output Subsidies in Mixed Markets', Economics Letters, 118(2): 293-296.

Lin, H. L. and H. Ogawa, 2005, 'Cost-reducing incentives in a mixed duopoly market', Economics Bulletin, 12: 1-6.

Matsumura, T., 1998, 'Partial privatization in mixed duopoly', Journal of Public Economics, 70: 473-483.

Matsumura, T. and A. Ogawa, 2012, 'Price versus quantity in a mixed duopoly', Economics Letters, 116: 174-177.

Nett, L., 1994, 'Why private firms are more innovative than the public firms', European Journal of Political Economy, 10: 639-653.

Nishimori, A. and H. Ogawa, 2002, 'Public monopoly, mixed oligopoly and productive efficiency', Australian Economic Papers, 41: 185-190

Pal, D. and M.D. White, 1998, 'Mixed oligopoly, privatization, and strategic trade policy', Southern Economic Journal, 65: 264-281.

Scrimitore, M., 2013, Price or quantity? the strategic choice of subsidized firms in a mixed duopoly', Economics Letters, 118: 337-341.

Singh, N. and X. Vives, 1984, 'Price and quantity competition in a differentiated duopoly', Rand Journal of Economics, 15: 546-554. 
Tanaka, Y., 2001a, 'Profitability of price and quantity strategies in an oligopoly', Journal of Mathematical Economics, 35(3): 409-418.

Tanaka, Y., 2001b, 'Profitability of price and quantity strategies in a duopoly with vertical product differentiation', Economic Theory, 17(3): 693-700.

Tasnádi, A., 2006, 'Price vs. quantity in oligopoly games', International Journal of Industrial Organization, 24(3): 541-554.

Tirole, J., 1988, The theory of industrial organization, MIT Press, Cambridge.

Townsend, R.F., J. Kirsten and N. Vink, 1998, 'Farm size, productivity and returns to scale in agriculture revisited: a case study of wine producers in South Africa', Agricultural Economics, 19: 175-180. 